\title{
Prognostic Value of Serum Magnesium in Mortality Risk among Patients on Hemodialysis: A Meta-Analysis of Observational Studies
}

\author{
Hongwei Wu ${ }^{a}$ Qiang Li ${ }^{b} \quad$ Lijing Fan $^{a}$ Dewang Zenga, c Xianggeng Chi d, e \\ Baozhang Guan ${ }^{a}$ Bo Hu ${ }^{a}$ Yongping Lu ${ }^{a}$ e Chen Yun $^{e}$ Bernhard Krämer ${ }^{e}$ \\ Berthold Hocher ${ }^{a}$ e Fanna Liu ${ }^{a}$ Lianghong Yin ${ }^{a}$ \\ aDepartment of Nephrology, The First Affiliated Hospital of Jinan University, Jinan University, Guangzhou, China; \\ ${ }^{b}$ Department of Nephrology, Dongguan Hospital of Traditional Chinese Medicine, Dongguan, China; 'Department \\ of Nephrology, Huadu District People's Hospital, Guangzhou, China; ${ }^{\mathrm{d} D e p a r t m e n t}$ of Nephrology, The First Affiliated

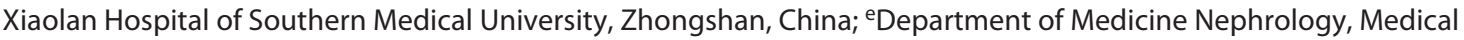 \\ Faculty Mannheim Heidelberg University, Mannheim, Germany
}

\section{Keywords}

Serum magnesium · Mortality $\cdot$ Hemodialysis ·

Meta-analysis

\begin{abstract}
Background: Previous studies have reported that serum magnesium (Mg) deficiency is involved in the development of heart failure, particularly in patients with end-stage kidney disease. The association between serum Mg levels and mortality risk in patients receiving hemodialysis is controversial. We aimed to estimate the prognostic value of serum Mg concentration on all-cause mortality and cardiovascular mortality in patients receiving hemodialysis. Methods: We did a systematic literature search in PubMed, EMBASE, Cochrane Library, and Web of Science to identify eligible studies that reported the prognostic value of serum $\mathrm{Mg}$ levels in mortality risk among patients on hemodialysis. We performed a meta-analysis by pooling and analyzing hazard ratios (HRs) and 95\% confidence intervals (Cls). Results: We identified 13 observational studies with an overall sample of 42,967 hemodialysis patients. Higher all-cause mortality (adjusted HR 1.58
\end{abstract}

karger@karger.com www.karger.com/kdd

Karger $\frac{1}{\%}$

GOPEN ACCESS
(C) 2020 The Author(s)

Published by S. Karger AG, Basel

This article is licensed under the Creative Commons AttributionNonCommercial-NoDerivatives 4.0 International License (CC BYNC-ND) (http://www.karger.com/Services/OpenAccessLicense) Usage and distribution for commercial purposes as well as any distribution of modified material requires written permission.
[95\% Cl: 1.31-1.91]) and higher cardiovascular mortality (adjusted HR 3.08 [95\% Cl: 1.27-7.50]) were found in patients with lower serum Mg levels after multivariable adjustment. There was marked heterogeneity $\left(I^{2}=79.6 \%, p<0.001\right)$ that was partly explained by differences in age stratification and study area. In addition, subgroup analysis showed that a serum $\mathrm{Mg}$ concentration of $\leq 1.1 \mathrm{mmol} / \mathrm{L}$ might be the vigilant cutoff value. Conclusion: A lower serum Mg level was associated with higher all-cause mortality and cardiovascular mortality in patients receiving hemodialysis.

(c) 2020 The Author(s)
Published by S. Karger AG, Basel

\section{Introduction}

Magnesium ion $\left(\mathrm{Mg}^{2+}\right)$ is important for maintaining neuromuscular irritability and participates in multiple physiological activities, including material and energy metabolism [1]. Previous studies indicated that $\mathrm{Mg}^{2+} \mathrm{de}-$

Hongwei Wu and Qiang Li contributed equally. 
ficiency was associated with an increased incidence of diabetes mellitus, metabolic syndrome, myocardial infarction, and stroke [2-5] by mediating vascular constriction, platelet aggregation, inflammation, and oxidative stress $[6,7]$, showing that $\mathrm{Mg}^{2+}$ is indispensable in homeostasis.

Magnesium plays a significant role in the function of the cardiovascular system [8]. Guidelines by KDIGO (Kidney Disease: Improving Global Outcomes) provide therapeutic recommendations for phosphate and calcium management but not $\mathrm{Mg}$. The value of serum $\mathrm{Mg}$ in vascular calcification has always been underestimated and generally neglected, especially in patients on hemodialysis (HD). Dialysis patients have a higher risk of hypomagnesemia due to low $\mathrm{Mg}$ concentration dialysate, decreased $\mathrm{Mg}$ intake [9], and side effects of some drugs. Hypomagnesemia might be a pivotal factor that contributes to 2 - to 5-fold more coronary artery calcification and higher allcause mortality in maintenance dialysis patients compared with age-matched individuals [10]. Actually, several convincing animal studies and clinical trials have established a correlation between serum $\mathrm{Mg}$ and vascular calcification $[11,12]$. However, the association between serum $\mathrm{Mg}$ and mortality outcomes among patients on HD remains controversial. Recognizing that individual studies might not be able to provide sufficient data on their own, we systematically reviewed original studies and performed a meta-analysis to assess the prognostic value of serum $\mathrm{Mg}$ levels on mortality risk in maintenance hemodialysis (MHD) patients.

\section{Methods}

Search Strategy and Selection Criteria

This meta-analysis was reported in accordance with the Preferred Reporting Items for Systematic Reviews and Meta-Analyses (PRISMA) statement. This study has been registered in PROSPERO with registration number CRD42019126266.

We performed a systematic literature search in EMBASE, PubMed, Cochrane Library, and Web of Science to identify relevant studies. The complete search strategy for PubMed and EMBASE is shown in online suppl. Table 1 (for all online suppl. material, see www.karger.com/doi/10.1159/000510513). We also performed a manual search by using the reference lists of pertinent primary articles. Studies were considered without language restrictions. The search was last updated on June 7, 2020.

\section{Study Selection and Data Extraction}

Inclusion criteria were as follows: (1) cohort studies or clinical trials reporting the association of serum $\mathrm{Mg}$ with all-cause or cardiovascular mortality in MHD patients; (2) reports of hazard ratio (HR) together with 95\% confidence interval (CI); or (3) sufficient data for HR extraction from Kaplan-Meier curves. A follow-up time of less than 3 months was excluded in this study. No restric-

A Meta-Analysis of Serum Magnesium

and Mortality in HD Patients tion was imposed on the dialysis modality or duration or sex and race of the study subjects. The primary outcome of interest was all-cause mortality and cardiovascular mortality after the initiation of HD therapy.

Two investigators (H.W. and Q.L.) independently evaluated titles and abstracts of all candidate articles based on participants, outcomes, and study designs. Full texts of selected articles were read further, and data were extracted by 2 authors (H.W. and Q.L.). Articles without consensus were evaluated by a third reviewer (L.F.), who would decide whether to include the articles. A modified version of the Newcastle-Ottawa Scale (NOS) (range 0-9) was applied to assess the quality of the included studies. Studies with scores $\geq 7$ were judged as high quality. We extracted the following data from all selected studies: author, country, year of publication, number of each trial, average age, follow-up time, serum Mg cutoff value, and HR and 95\% CI of all-cause mortality and cardiovascular mortality performed by univariate analysis and multivariate analysis.

\section{Statistical Analysis}

We pooled HR and $95 \%$ CI data from each study. A $p$ value $<0.05$ showed significant difference. If studies presented multiple adjusted models and categorized serum $\mathrm{Mg}$, the last model and the lowest serum $\mathrm{Mg}$ group were utilized for merging. We further discussed the overall influence of diverse adjusted models and grouping in subgroup analysis. For articles that did not directly provide HR for mortality, we extracted data from Kaplan-Meier curves and used the method from Tierney et al. [13] to estimate the HR and 95\% CI. Cochran's $Q$ test and Higgins' $I^{2}$ statistic were taken to assess the heterogeneity of the included trials. An $I^{2}>50 \%$ suggested significant heterogeneity. Subgroup analysis, sensitivity analysis, and meta-regression were applied to explore the origin of heterogeneity. Publication bias was assessed by funnel plot, Begg's rank correlation test, and Egger's linear regression test ( $p<0.05$ was considered a noteworthy publication bias). The trim and fill method [14] was applied to test and adjust for publication bias. In addition, a contour-enhanced meta-analysis funnel plot [15] was performed to predict the influence of unknown research studies on our findings. All analyses were carried out by the STATA statistical software version 12.0 (STATA, College Station, TX, USA).

\section{Results}

\section{Study Selection}

We identified 524 titles (137 in PubMed, 255 in Web of Science, 98 in EMBASE, 32 in Cochrane, and 2 in references). Of these, 20 articles were set aside for further assessment after a screening of abstracts and full-text reading. In the process of data extraction, we found 1 article on a randomized controlled experiment [16] that was unsuitable for data integration with the remaining observational studies. A study by Sakaguchi et al. [17] was excluded due to lack of HR and available Kaplan-Meier curves. We identified 2 studies $[18,19]$ about peritoneal dialysis that were not suitable for data merging. Adjusted 
Table 1. The basic information of the included studies

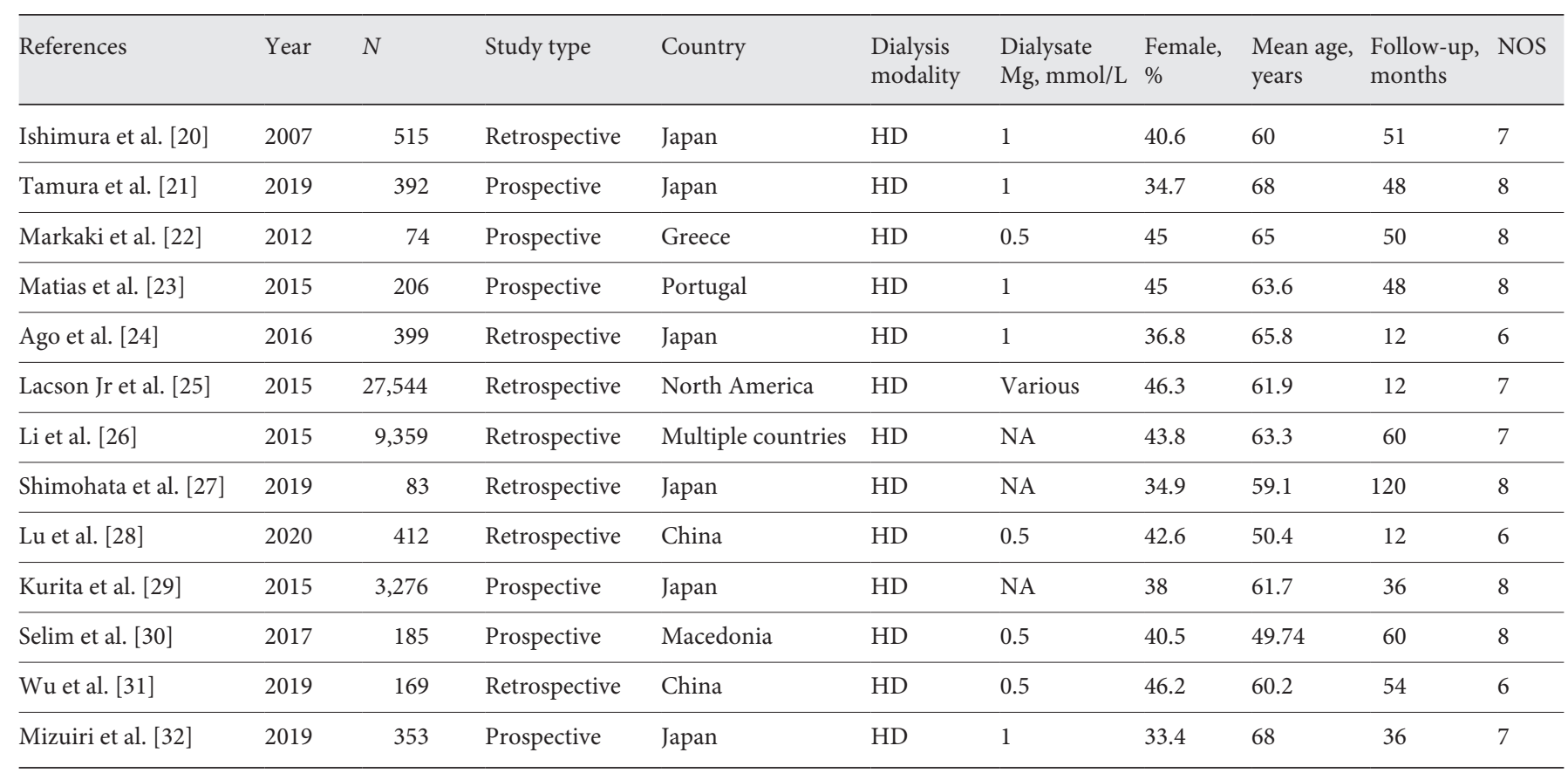

NOS, Newcastle-Ottawa Scale; HD, hemodialysis; PD, peritoneal dialysis; NA, not available.

Fig. 1. Flowchart of the selection process of

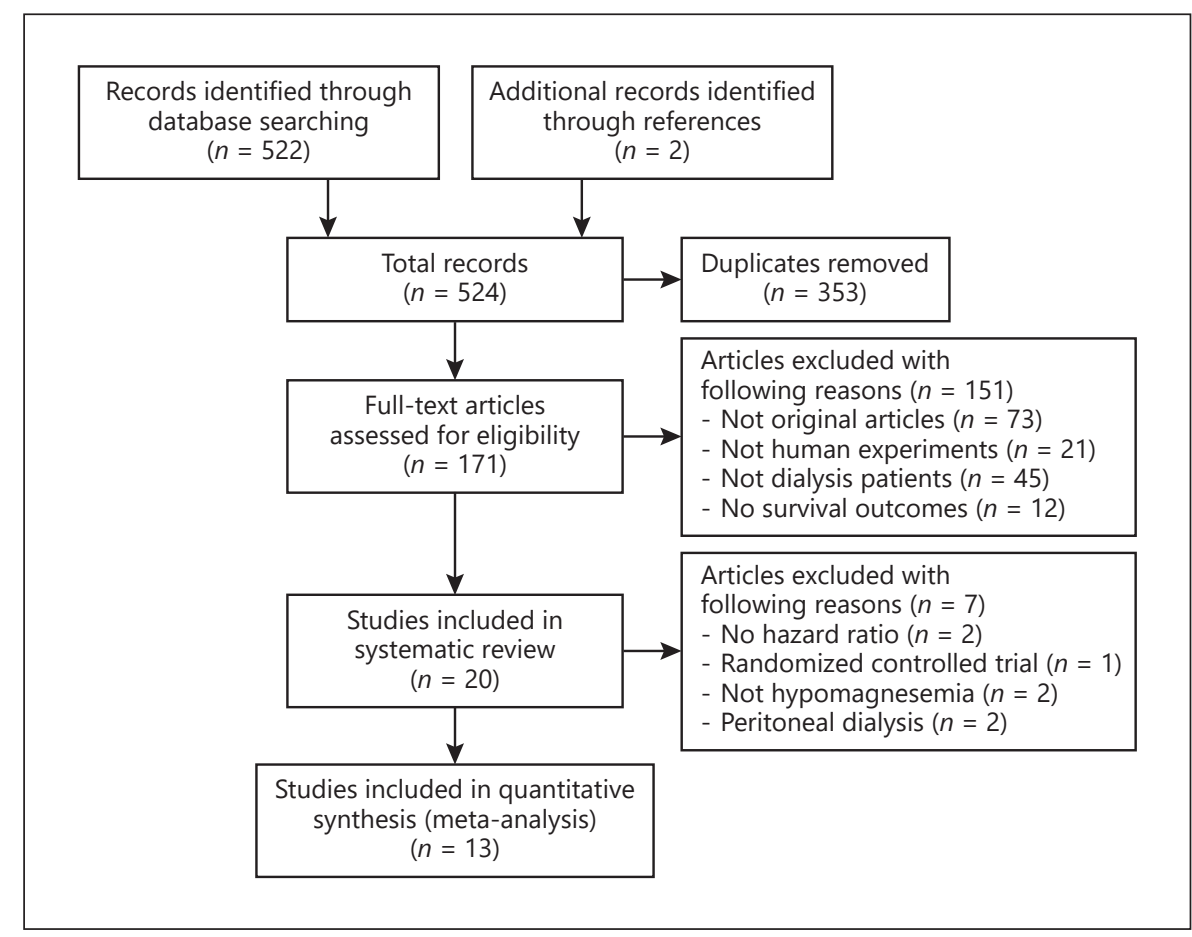
included studies. 
Table 2. Association between serum magnesium and all-cause and cardiovascular mortality in maintenance dialysis patients

\begin{tabular}{|c|c|c|c|c|c|}
\hline \multirow[t]{2}{*}{ References } & \multicolumn{2}{|l|}{ All-cause mortality } & \multicolumn{2}{|c|}{ Cardiovascular mortality } & \multirow{2}{*}{$\begin{array}{l}\text { Serum Mg level, } \\
\mathrm{mmol} / \mathrm{L}\end{array}$} \\
\hline & $\begin{array}{l}\text { adjusted HR } \\
(95 \% \mathrm{Cl})\end{array}$ & $\begin{array}{l}\text { unadjusted HR } \\
(95 \% \mathrm{Cl})\end{array}$ & $\begin{array}{l}\text { adjusted HR } \\
(95 \% \mathrm{Cl})\end{array}$ & $\begin{array}{l}\text { unadjusted HR } \\
(95 \% \mathrm{Cl})\end{array}$ & \\
\hline Ishimura et al. [20] & $1.14(1.02,1.60)$ & NA & NA & NA & $<1.1$ vs. $\geq 1.1$ \\
\hline Tamura et al. [21] & $2.43(0.82,10.23)$ & NA & $2.67(0.64,12.43)$ & NA & $<1.1$ vs. $\geq 1.2$ \\
\hline Markaki et al. [22] & $1.16(0.34,3.96)$ & NA & NA & NA & $\leq 1$ vs. $>1$ \\
\hline Matias et al. [23] & $1.15(1.02,1.14)$ & NA & $1.22(1.05,1.39)$ & NA & $\leq 1.15$ vs. $>1.15$ \\
\hline Ago et al. [24] & $2.41(1.47,4.20)$ & $2.84(1.45,3.43)$ & NA & NA & $\leq 0.9$ vs. $>0.9$ \\
\hline Lacson Jr et al. [25] & $1.12(0.92,1.35)$ & $1.47(1.22,1.79)$ & NA & NA & $>0.80-0.95$ vs. $\geq 1.25$ \\
\hline Li et al. [26] & $\begin{array}{l}1.39(1.23,1.58) \\
1.20(1.06,1.36)\end{array}$ & $\begin{array}{l}1.63(1.44,1.85) \\
1.30(1.15,1.40)\end{array}$ & NA & NA & $\begin{array}{l}<0.82 \text { vs. } \geq 0.9-0.98 \\
<0.74 \text { vs. } \geq 0.74-0.82\end{array}$ \\
\hline Shimohata et al. [27] & $2.73(1.07,6.94)$ & $2.89(1.39,6.06)$ & NA & NA & $<1.0$ vs. $\geq 1.0$ \\
\hline Lu et al. [28] & $3.53(1.59,7.84)$ & NA & $4.29(1.42,12.91)$ & NA & $<1.0$ vs. $\geq 1.0$ \\
\hline Kurita et al. [29] & $\begin{array}{l}1.73(1.20,2.50) \\
1.65(1.23,2.21)\end{array}$ & $\begin{array}{l}2.38(1.71,3.31) \\
1.74(1.29,2.35)\end{array}$ & NA & NA & $\begin{array}{l}\leq 0.95 \text { vs. } \geq 1.03-1.88 \\
>0.95-1.03 \text { vs. } \geq 1.03-1.88\end{array}$ \\
\hline Selim et al. [30] & $\begin{array}{l}1.14(0.44,2.89) \\
0.95(0.38,2.35)\end{array}$ & $\begin{array}{l}2.34(1.26,4.33) \\
0.82(0.44,1.51)\end{array}$ & NA & NA & $\begin{array}{l}<1.1 \text { vs. } \geq 1.1-1.30 \\
>1.30 \text { vs. } \geq 1.1-1.30\end{array}$ \\
\hline Wu et al. [31] & $8.3(4.26,16.19)$ & $9.54(5.37,16.96)$ & $9.72(3.25,29.1)$ & $11.21(4.27,29.45)$ & $<1.0$ vs. $\geq 1.0$ \\
\hline Mizuiri et al. [32] & $2.17(0.96,5.02)$ & $2.79(1.84,4.27)$ & $2.56(0.72,10.36)$ & $3.73(2.07,6.98)$ & $<1.0$ vs. $\geq 1.0$ \\
\hline
\end{tabular}

$\mathrm{HR}$, hazard ratio; CI, confidence interval; NA, not available.

HRs and 95\% CIs were not provided in 2 articles [20, 21], and we, therefore, extracted data from the Kaplan-Meier curves. Finally, 13 candidate articles [20-32] were incorporated into quantitative synthesis (meta-analysis). The flowchart is shown in Figure 1.

\section{Study Characteristics}

The included articles were published between 2007 and 2020, involving 42,967 patients on HD. The characteristics of the included studies are shown in Table 1.

A total of 13 observational studies were eligible for data merging, including 6 prospective cohort studies and 7 retrospective studies. The average age of participants in included studies ranged from 49.3 to 68 years. The mean follow-up ranged from 12 to 120 months. All the studies examined the relationship between serum Mg levels and all-cause mortality among HD patients, with $5[21,23,28,31,32]$ also evaluating the association between serum $\mathrm{Mg}$ and cardiovascular mortality. All the studies calculated HRs by multivariate analysis, and 8 [24-27, 29-32] also used univariate analysis. Catego- rized serum $\mathrm{Mg}$ concentration was provided in 3 studies $[26,29,30]$. We selected the lowest serum Mg group to pool HRs. For detailed information about HRs and grouping, see Table 2.

The NOS was applied to assess the quality of included studies. A total of 10 studies were of high quality ( $\geq 7$ score), and 3 were of moderate quality ( $4-7$ score). The NOS grade for each included study is shown in online suppl. Table 2.

\section{Association of Serum Mg with All-Cause Mortality}

Our merged results of interest, the adjusted/unadjusted HRs and 95\% CIs about the correlation between serum $\mathrm{Mg}$ and all-cause mortality, are reported in Figure 2. Among the 13 included studies, 8 indicated that a lower serum $\mathrm{Mg}$ level was an independent risk factor for allcause mortality $(p<0.05)[20,23,24,26-29,31]$, and 5 studies did not reach statistical significance $[21,22,25,30$, 32]. After pooling, our findings showed that compared with higher serum $\mathrm{Mg}$ groups, lower serum $\mathrm{Mg}$ levels increased all-cause mortality among HD patients (adjusted 


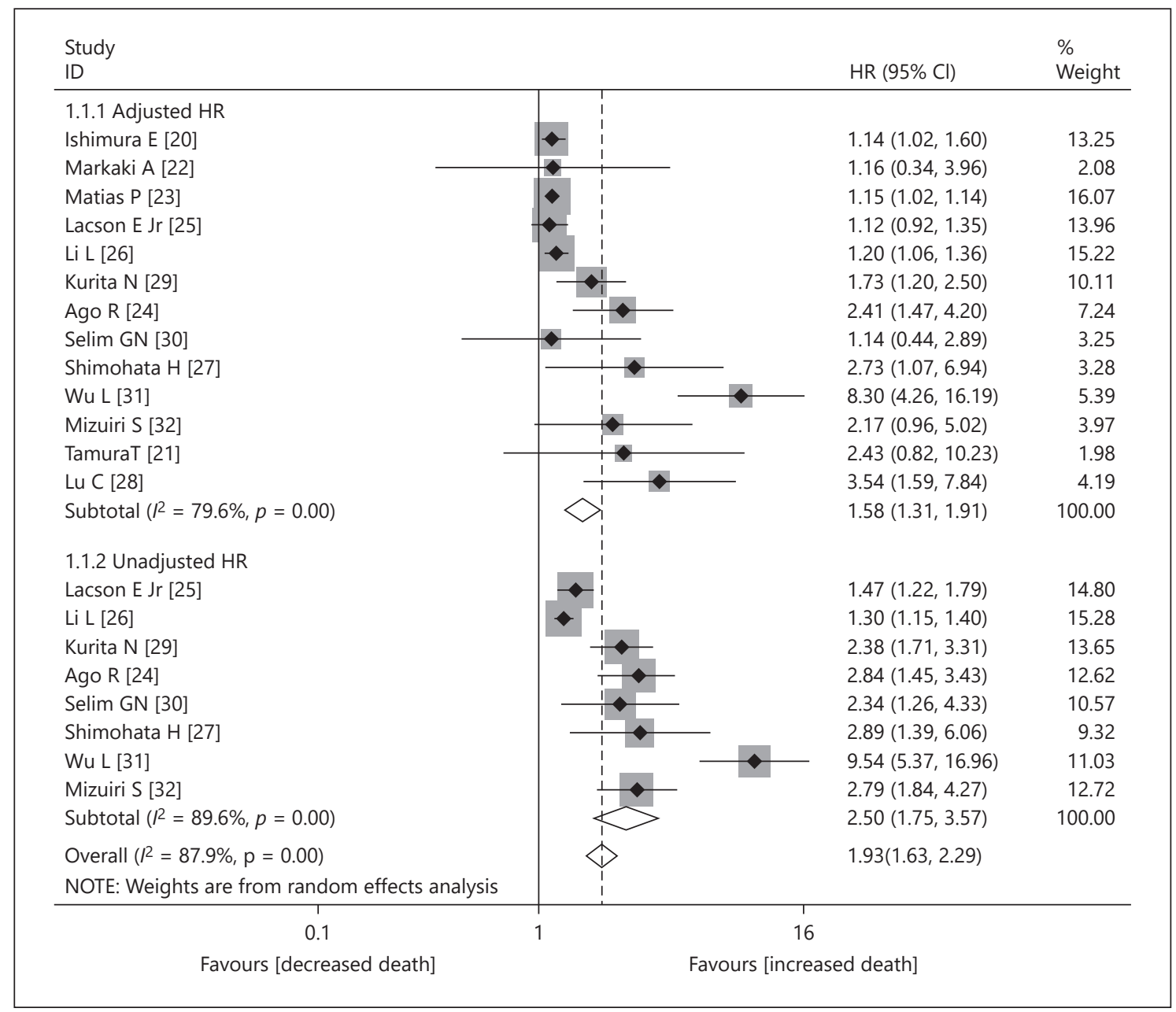

Fig. 2. The association between serum Mg levels and all-cause mortality among patients on dialysis (low vs. high Mg groups).

HR 1.58 [95\% CI: 1.31-1.91] and unadjusted HR 2.5 [95\% CI: $1.75-3.57])$.

Interstudy heterogeneity was found $\left(I^{2}=79.6 \%, p<\right.$ 0.001 ). To assess the heterogeneity, we performed subgroup analysis. We found that difference in age stratification and study area could partly explain the heterogeneity (online suppl. Table 3). Meta-regression also suggested that studies in different countries contributed to $29.8 \%$ of the observed heterogeneity ( $p=0.046$ ) (online suppl. Fig. 1 ). In the sensitivity analysis, the overall estimate of effect did not change meaningfully after excluding 1 article at a time (online suppl. Fig. 2). The $I^{2}$ value dropped to $48.1 \%$ after the study by $\mathrm{Wu}$ et al. [31] was excluded, with a materially unchanged result (adjusted HR 1.33 [95\% CI: 1.16-1.52, $p=0.01]$ ).

As cutoff values of low serum $\mathrm{Mg}$ concentration differed from each study, we further analyzed the effects of different serum $\mathrm{Mg}$ concentration on overall survival. The results showed that concentrations of $\mathrm{Mg} \leq 0.75$ $\mathrm{mmol} / \mathrm{L}$ (HR 1.20 [95\% CI: 1.06-1.36]), $\mathrm{Mg} \leq 0.9 \mathrm{mmol} / \mathrm{L}$ (HR 1.59 [95\% CI: 1.02-2.49]), and $\mathrm{Mg} \leq 1.1 \mathrm{mmol} / \mathrm{L}$ (HR 1.89 [95\% CI: 1.37-2.61]) were risk factors for all-cause mortality, except $\mathrm{Mg}>1.1 \mathrm{mmol} / \mathrm{L}$, which did not reach statistical significance (HR 0.95 [95\% CI: $0.38-2.36, p>$ 0.05]) (Fig. 3). It seems that a serum Mg concentration of $\leq 1.1 \mathrm{mmol} / \mathrm{L}$ might be the vigilant cutoff value.

\section{Influence of Serum Mg Levels on Cardiovascular Mortality Risk}

We included 5 studies $[21,23,28,31,32]$ in the evaluation of cardiovascular mortality. We found that a lower serum Mglevel increased cardiovascular mortality among patients receiving dialysis (adjusted HR 3.08 [95\% CI: 


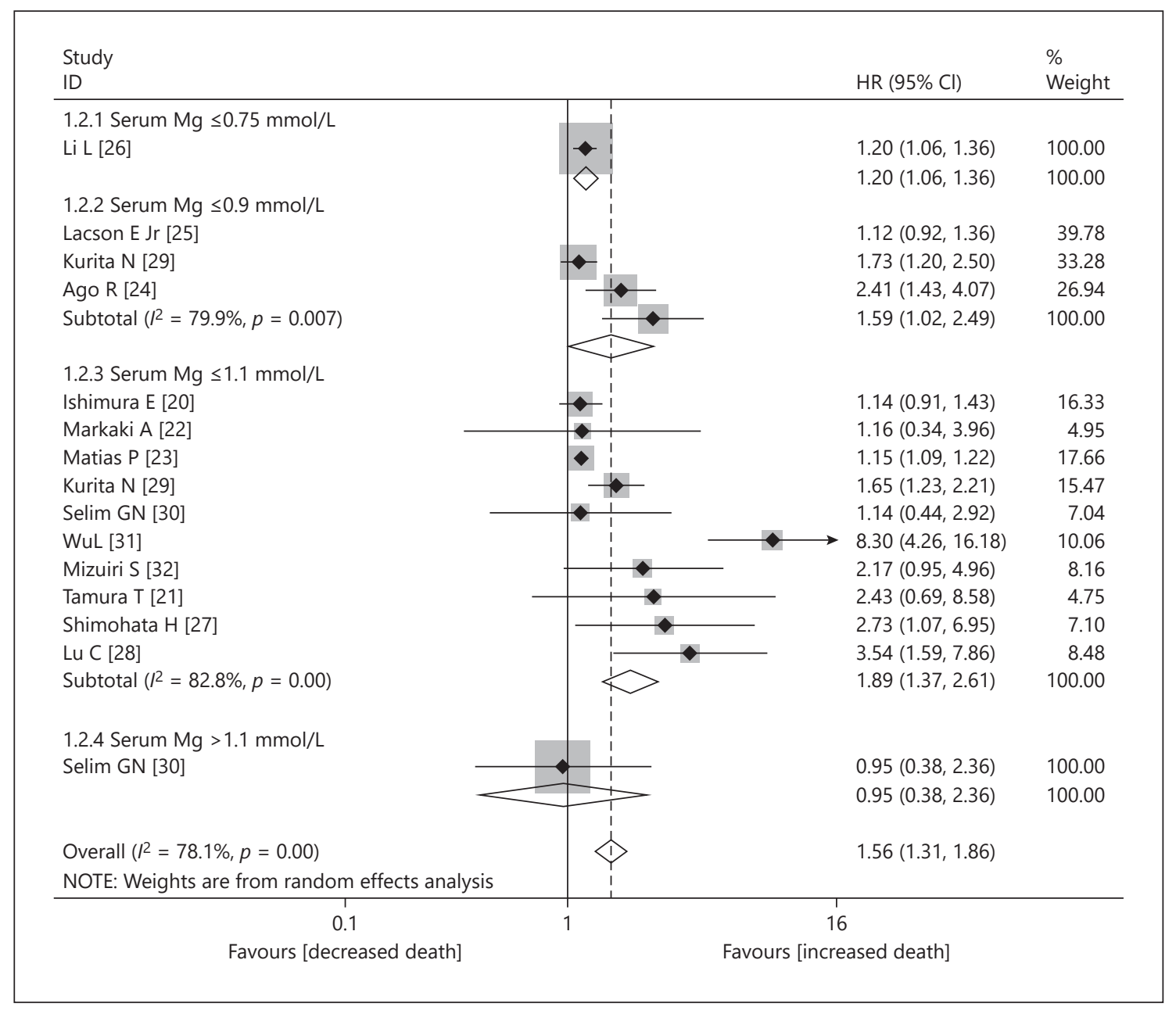

Fig. 3. Subgroup analysis by Mg cutoff level on all-cause mortality (low vs. high Mg groups).

1.27-7.50], $p<0.001$, and unadjusted HR 6.05 [95\% CI: 2.07-17.65], $p<0.001$ ) (Fig. 4).

\section{Publication Bias}

Publication bias was evident in the asymmetric funnel plot and Egger's test ( $p=0.009$ ) (Fig. 5 and online suppl. Fig. 3). Subsequently, we used the trim-and-fill method to adjust for publication bias. After the addition of 4 articles to this model, the adjusted HR did not change significantly (HR 1.32 [95\% CI: 1.06-1.62, $p=0.01]$ ) (Fig. 5 and online suppl. Fig. 4), indicating that existing publication bias had little effect on our results. Furthermore, we performed the contour-enhanced meta-analysis funnel plot to predict the influence of unknown research on our findings (online suppl. Fig. 5). We found that future research will most likely have a meaningful impact on current results; thus, more investigations are essential in the future.

A Meta-Analysis of Serum Magnesium and Mortality in HD Patients

\section{Discussion}

$\mathrm{Mg}^{2+}$ plays a key role in the maintenance of homeostasis, and previous studies have reported the prognostic value of serum $\mathrm{Mg}$ levels in patients receiving dialysis. However, the results of those studies remain inconsistent. We targeted the HD population, which has both a high prevalence of serum $\mathrm{Mg}$ deficiency and a high early mortality rate, and performed a meta-analysis to obtain a more comprehensive estimation of mortality risk associated with serum Mg levels.

After data merging, we found that lower serum $\mathrm{Mg}$ level was associated with increased all-cause mortality and cardiovascular mortality in HD patients, despite 5 studies that did not reach statistical significance. These findings are consistent with the results found for peritoneal dialysis patients $[18,19]$, revealing that low Mg con- 


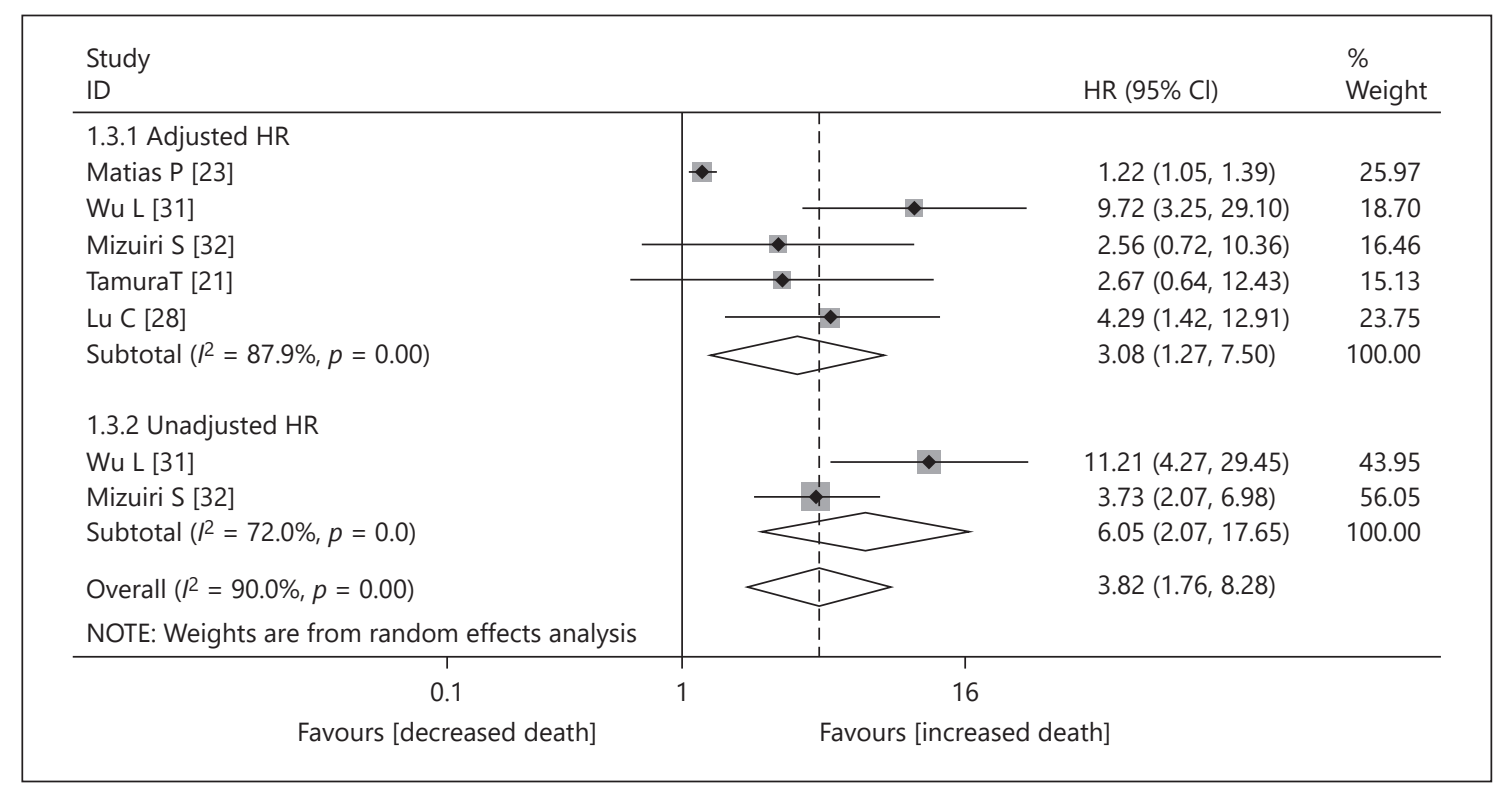

Fig. 4. The association between serum Mg levels and cardiovascular mortality risk (low vs. high Mg groups).

centrations have negative effects on both $\mathrm{HD}$ and $\mathrm{PD}$ patients. It should be noted that heterogeneity existed among the included studies, and differences in age stratification and study area could partly explain the heterogeneity after subgroup analysis and meta-regression. Importantly, subgroup analysis showed that the pooled results from studies in the Europe area did not reach statistical significance, indicating that our findings might be more practical in Asia. Studies have documented international variation in prevalence, patient survival, and patterns of medical practice related to dialysis [33, 34]; thus, the practicability and feasibility of our results in different countries also need to be further explored. Our findings primarily depended on baseline $\mathrm{Mg}$ measurement. In fact, serum $\mathrm{Mg}$ concentrations in $\mathrm{HD}$ patients tend to decrease slightly with $0.011 \mathrm{mmol} / \mathrm{L} /$ year [16] due to reduced dietary intake, dialytic clearance, and concomitant medications. The risk of variation in $\mathrm{Mg}$ levels has been largely ignored in HD patients. A study of 169 MHD patients reported that a group with high variation in $\mathrm{Mg}(\Delta \mathrm{Mg} \geq 0.149 \mathrm{mmol} / \mathrm{L})$ had a higher all-cause mortality than the group with middle variation $(0.114 \leq \Delta \mathrm{Mg}$ $<0.149 \mathrm{mmol} / \mathrm{L}$ ), despite multivariate Cox regression analysis indicating that serum $\mathrm{Mg}$ variability was not an independent factor for all-cause mortality or cardiovascular mortality [31]. Further investigation of the relationship between $\mathrm{Mg}$ variability and mortality is imperative.

The warning threshold for serum $\mathrm{Mg}$ concentration in mortality prediction is difficult to determine. A study by Sakaguchi et al. [17] revealed a J-shaped relevancy between all-cause mortality and serum Mg concentrations in HD patients, with a "sweet spot" around 1.2 $\mathrm{mmol} / \mathrm{L}$. Similar findings were determined in a study of patients from the United States that indicated that the best survival was observed for serum Mg levels of 1.25 $\mathrm{mmol} / \mathrm{L}$ [25]. Subgroup analysis in our study suggested that serum $\mathrm{Mg}$ concentration $\leq 1.1 \mathrm{mmol} / \mathrm{L}$ might be the vigilant cutoff value. Notably, a meta-analysis performed by Angkananard et al. [35] concluded that hypermagnesemia $(\mathrm{Mg} \geq 1.05 \mathrm{mmol} / \mathrm{L})$ was correlated with increased all-cause mortality, but this was not observed for hypomagnesemia. Although this finding was limited to patients with chronic heart failure not on dialysis, we should recognize that excessive $\mathrm{Mg}$ concentration was also likely to pose a risk, especially in an elderly population. In fact, extreme concentrations of serum $\mathrm{Mg}(<0.7$ $\mathrm{mmol} / \mathrm{L}$ or $>1 \mathrm{mmol} / \mathrm{L}$ ) is a common ionic disorder with high risk of adverse clinical outcomes. Hypermagnesemia is speculated to cause excessive inhibition of parathyroid hormone and adverse effects of other mineral metabolism (osteomalacia) [36], while hypomagnesemia can lead to endothelial dysfunction and induce cardiac arrhythmias. Therefore, addressing the issue of when and how to start $\mathrm{Mg}$ supplementation is an urgent need.

Clearly, serum Mg concentrations are affected by dialysis prescription to a large extent. More recently, a study reported that $33 \%$ of patients developed hypomagnese- 

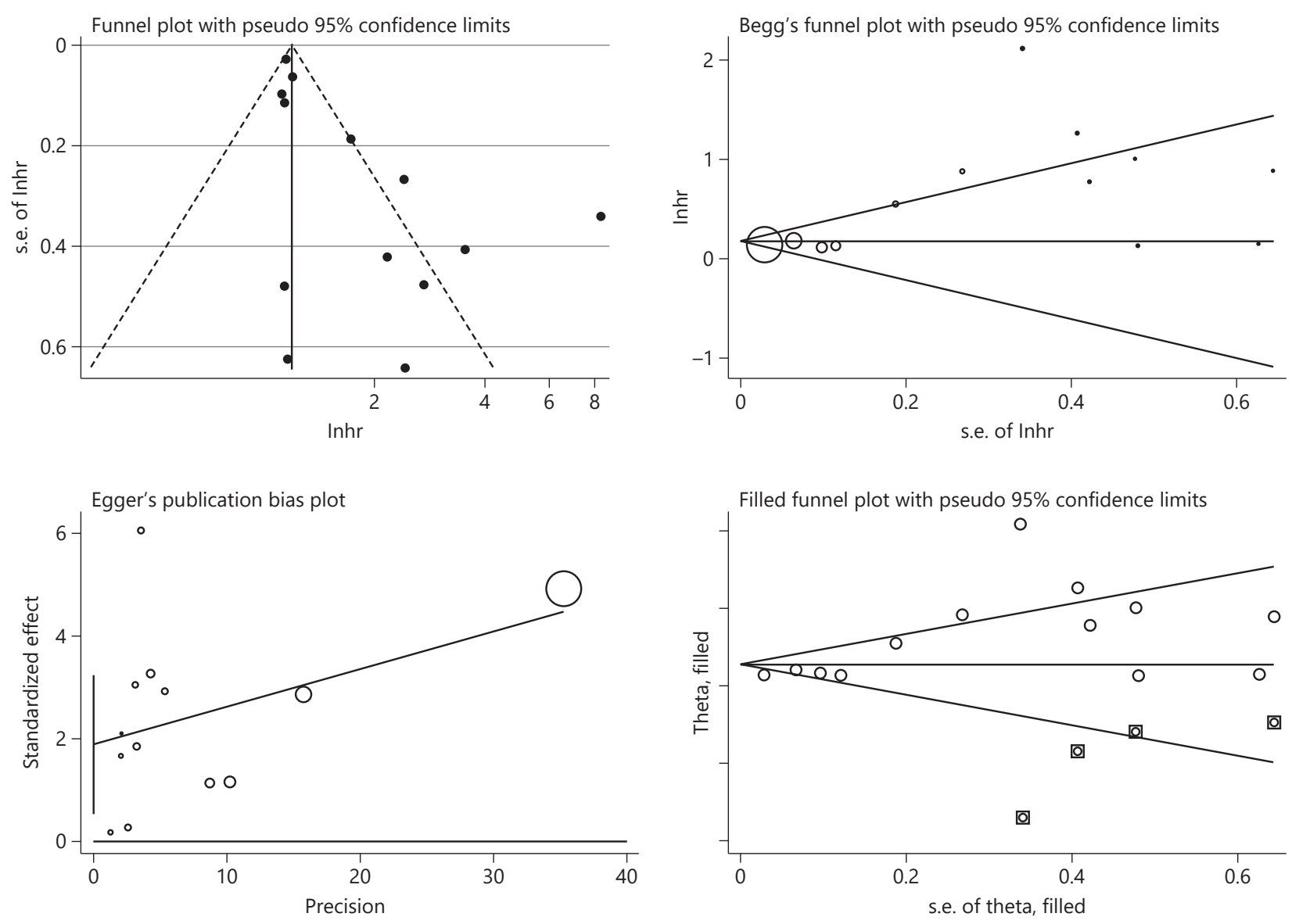

Fig. 5. Funnel plot of the association between serum $\mathrm{Mg}$ and all-cause mortality. a The funnel plot with pseudo 95\% confidence intervals (CIs). b Begg's funnel plot with pseudo 95\% CIs. c Egger's publication bias plot. d Trimmed and filled funnel plot with pseudo 95\% CIs.

mia with dialysate $\mathrm{Mg}$ of $0.25 \mathrm{mmol} / \mathrm{L}$, while only $5 \%$ of patients exposed to dialysate $\mathrm{Mg}$ of $0.5 \mathrm{mmol} / \mathrm{L}$ developed hypomagnesemia [37]. Importantly, interactions between dialysate $\mathrm{Mg}$ concentrations and other dialysate constituents should be recognized, especially potassium content. Low Mg dialysate could raise risk of arrhythmia and myocardial infarction associated with low potassium dialysate, considering the effect of hypomagnesemia on the risk of hypokalemia by promoting intracellular potassium shifts [38]. Therefore, the risk of fatal arrhythmia caused by the overlaying of hypokalemia and hypomagnesemia must be avoided. Given the adverse effects of hypomagnesemia, hypermagnesemia, and hypokalemia, higher $\mathrm{Mg}$ dialysate levels of $0.5-1 \mathrm{mmol} / \mathrm{L}$ are recommended, which is comparable with the dialysate Mg concentrations in our included studies. Additionally, proton pump inhibitors are believed to have the potential to lower serum Mg concentrations in HD patients with nutritional issues [37], which should also be brought to our attention. So, what is the optimal dose for $\mathrm{Mg}$ supplementation? Studies have showed that Mg supplementation improved flow-mediated dilatation and enhanced exercise tolerance $(365 \mathrm{mg} / \mathrm{d})$ [39] as well as decreased carotid intima-media thickness in HD patients (610 mg every other day) [40]. Moreover, results from meta-analysis supported that increasing dietary Mg intake (per $100 \mathrm{mg} /$ day increment) was related to reduced risk of ischemic stroke [41], heart failure, and all-cause mortality [42]. However, a special Mg supplement guideline aimed at the dialysis population is essential due to differing $\mathrm{Mg}^{2+} \mathrm{ab}-$ sorption and excretion abilities of dialysis patients from those of healthy subjects. Meanwhile, Mg concentration 
must be carefully monitored during interventions because the safety of high Mg levels has not yet been proven.

$\mathrm{Mg}$ acts as a calcification inhibitor through multiple molecular mechanisms [43]. First, the entry of calcium into the cells is inhibited because calcium channels are antagonized by $\mathrm{Mg}^{2+}[44]$. Second, $\mathrm{Mg}$ can inhibit the transformation from amorphous $\mathrm{Ca} / \mathrm{P}$ to a hydroxyapatite forming dissolvable whitlockite $[45,46]$. Third, via transient receptor potential melastatin $7, \mathrm{Mg}^{2+}$ restores the balance between expression of calcification promotors and inhibitors by preventing the loss of BMP-7 and suppressing expression of osteogenic transcription factors (BMP-1, RUNX-2, and SRY-box9) [11, 47], preventing vascular smooth muscle cell from osteoblastic conversion and calcification. Furthermore, it has been certified that $\mathrm{Mg}^{2+}$ could act on the CaSR and further inhibit vascular smooth muscle cell calcification [48]. Therefore, dialysis patients with low serum $\mathrm{Mg}$ concentrations have a higher risk of vascular calcification and cardiovascular events.

Our study was restricted by several factors. First, significant heterogeneity was observed among the included studies, which was partly explained by differences in the average age of the study population as well as study geographic location. Second, potential residual confounding could not be excluded because adjusted HRs from each study were confounded due to the possibility that adjustments were for different covariates. Third, only baseline serum $\mathrm{Mg}$ was tested, and the fact that $\mathrm{Mg}$ levels might change over time was ignored. Finally, the cutoff value of low $\mathrm{Mg}$ levels was not consistent which might also cause heterogeneity. In the future, randomized trials should investigate the limiting cutoff values of $\mathrm{Mg}$ concentration in predicting mortality and define the effects of Mg supplementation among patients on dialysis.
In summary, our meta-analysis of observational studies shows that a lower serum $\mathrm{Mg}$ level is associated with higher all-cause mortality and higher cardiovascular mortality in patients receiving HD. These findings could be of clinical significance in that the serum Mg levels could be a predictive factor for mortality among HD patients and a treatment strategy for Mg supplementation.

\section{Acknowledgements}

The authors thank Prof. Bin Wang from the Institute of Economics of Jinan university for providing help for statistical analysis.

\section{Statement of Ethics}

This study did not require approval because it does not contain any studies with human participants or animals performed by any of the authors.

\section{Conflict of Interest Statement}

The authors declare that they have no conflicts of interest to disclose.

\section{Funding Sources}

This work was supported by the Clinical Engineering of Blood Purification in Guangdong Province (507204531040).

\section{Author Contributions}

Research idea and study design: H.W., Q.L., and L.F.; data collection: D.Z., X.C., B.G., B.H., and C.Y.; data analysis: H.W. and Q.L.; manuscript writing: H.W.; language adviser: Y.L., B.K., and B.H.; manuscript modification: L.Y. and F.L.

\section{References}

1 Jahnen-Dechent W, Ketteler M. Magnesium basics. Clin Kidney J. 2012 Feb;5(Suppl 1):i3.

2 Dong JY, Xun P, He K, Qin LQ. Magnesium intake and risk of type 2 diabetes: meta-analysis of prospective cohort studies. Diabetes Care. 2011 sep;34(9):2116-22.

3 He K, Liu K, Daviglus ML, Morris SJ, Loria $\mathrm{CM}$, Van Horn L, et al. Magnesium intake and incidence of metabolic syndrome among young adults. Circulation. 2006 Apr;113(13): 1675-82.

4 Khan AM, Lubitz SA, Sullivan LM, Sun JX, Levy D, Vasan RS, et al. Low serum magnesium and the development of atrial fibrillation in the community: the Framingham Heart Study. Circulation. 2013 Jan;127(1):33-8.

5 Larsson SC, Orsini N, Wolk A. Dietary magnesium intake and risk of stroke: a meta-analysis of prospective studies. Am J Clin Nutr. 2012 Feb;95(2):362-6.

6 Kostov K, Halacheva L. Role of magnesium deficiency in promoting atherosclerosis, endothelial dysfunction, and arterial stiffening as risk factors for hypertension. Int J Mol Sci. 2018 Jun;19(6): 1724.

7 Maier JA. Endothelial cells and magnesium: implications in atherosclerosis. Clin Sci. 2012 May;122(9):397-407.
8 Mohammadifard N, Gotay C, Humphries $\mathrm{KH}$, Ignaszewski A, Esmaillzadeh A, Sarrafzadegan N. Electrolyte minerals intake and cardiovascular health. Crit Rev Food Sci Nutr. 2019 Apr;59(15):2375-85.

9 Carrero JJ, Aguilera A, Stenvinkel P, Gil F, Selgas R, Lindholm B. Appetite disorders in uremia. J Ren Nutr. 2008 Jan;18(1):107-13.

10 Braun J, Oldendorf M, Moshage W, Heidler R, Zeitler E, Luft FC. Electron beam computed tomography in the evaluation of cardiac calcification in chronic dialysis patients. Am J Kidney Dis. 1996 Mar;27(3): 394-401. 
11 Ter Braake AD, Shanahan CM, de Baaij JHF. Magnesium counteracts vascular calcification: passive interference or active modulation? Arterioscler Thromb Vasc Biol. 2017 Jun;37(8):1431-45.

12 Molnar AO, Biyani M, Hammond I, Harmon JP, Lavoie S, McCormick B, et al. Lower serum magnesium is associated with vascular calcification in peritoneal dialysis patients: a cross sectional study. BMC Nephrol. 2017 Apr; 18(1):129.

13 Tierney JF, Stewart LA, Ghersi D, Burdett S, Sydes MR. Practical methods for incorporating summary time-to-event data into metaanalysis. Trials. 2007 Jun;8:16.

14 Jennions MD, Møller AP. Publication bias in ecology and evolution: an empirical assessment using the 'trim and fill' method. Biol Rev Camb Philos Soc. 2002 May;77(2):211-22.

15 Peters JL, Sutton AJ, Jones DR, Abrams KR, Rushton L. Contour-enhanced meta-analysis funnel plots help distinguish publication bias from other causes of asymmetry. J Clin Epidemiol. 2008 Oct;61(10):991-6.

16 van Zuijdewijn CLR, Grooteman MP, Bots ML, Blankestijn PJ, Steppan S, Büchel J, et al. Serum magnesium and sudden death in European hemodialysis patients. PLoS One. 2015 Nov; 10(11):e0143104.

17 Sakaguchi Y, Fujii N, Shoji T, Hayashi T, Rakugi $\mathrm{H}$, Isaka $\mathrm{Y}$, et al. Hypomagnesemia is a significant predictor of cardiovascular and non-cardiovascular mortality in patients undergoing hemodialysis. Kidney Int. 2014 Jan; 85(1):174-81.

18 Ye H, Cao P, Zhang X, Lin J, Guo Q, Mao H, et al. Serum magnesium and cardiovascular mortality in peritoneal dialysis patients: a 5 -year prospective cohort study. Br J Nutr. 2018 Aug;120(4):415-23.

19 Yang X, Soohoo M, Streja E, Rivara MB, Obi Y, Adams SV, et al. Serum magnesium levels and hospitalization and mortality in incident peritoneal dialysis patients: a cohort study. Am J Kidney Dis. 2016 Oct;68(4):619-27.

20 Ishimura E, Okuno S, Yamakawa T, Inaba M, Nishizawa Y. Serum magnesium concentration is a significant predictor of mortality in maintenance hemodialysis patients. Magnes Res. 2007 Dec;20(4):237-44.

21 Tamura T, Unagami K, Okazaki M, Komatsu M, Nitta K. Serum magnesium levels and mortality in Japanese maintenance hemodialysis patients. Blood Purif. 2019 Apr;47(Suppl 2):88-94.

22 Markaki A, Kyriazis J, Stylianou K, Fragkiadakis GA, Perakis K, Margioris AN, et al. The role of serum magnesium and calcium on the association between adiponectin levels and all-cause mortality in end-stage renal disease patients. PLoS One. 2012 Dec;7(12):e52350.

23 Matias P, Azevedo A, Laranjinha I, Navarro D, Mendes M, Ferreira C, et al. Lower serum magnesium is associated with cardiovascular risk factors and mortality in haemodialysis patients. Blood Purif. 2014 Jan;38(3-4):24452.
24 Ago R, Shindo T, Banshodani M, Shintaku S, Moriishi M, Masaki T, et al. Hypomagnesemia as a predictor of mortality in hemodialysis patients and the role of proton pump inhibitors: a cross-sectional, 1-year, retrospective cohort study. Hemodial Int. 2016 Jun; 20(4):580-8.

25 Lacson E Jr, Wang W, Ma L, Passlick-Deetjen J. Serum magnesium and mortality in hemodialysis patients in the United States: a cohort study. Am J Kidney Dis. 2015 Dec;66(6): 1056-66.

26 Li L, Streja E, Rhee CM, Mehrotra R, Soohoo M, Brunelli SM, et al. Hypomagnesemia and mortality in incident hemodialysis patients. Am J Kidney Dis. 2015 Dec;66(6):1047-55.

27 Shimohata H, Yamashita M, Ohgi K, Tsujimoto R, Maruyama H, Takayasu M, et al. The relationship between serum magnesium levels and mortality in non-diabetic hemodialysis patients: a 10-year follow-up study. Hemodial Int. 2019 Jul;23(3):369-74.

28 Lu C, Wang Y, Wang D, Nie L, Zhang Y, Lei $\mathrm{Q}$, et al. Hypomagnesemia and short-term mortality in elderly maintenance hemodialysis patients. Kidney Dis. 2020 Mar;6(2):10918.

29 Kurita N, Akizawa T, Fukagawa M, Onishi Y, Kurokawa K, Fukuhara S. Contribution of dysregulated serum magnesium to mortality in hemodialysis patients with secondary hyperparathyroidism: a 3-year cohort study. Clin kidney J. 2015 Dec;8(6):744-52.

30 Selim GN, Spasovski G, Tozija L, Georgievska-Ismail L, Zafirova-Ivanovska B, MasinSpasovska J, et al. Hypomagnesemia and cause-specific mortality in hemodialysis patients: 5-year follow-up analysis. Int J Artif Organs. 2017 Oct;40(10):542-9.

31 Wu L, Cai K, Luo Q, Wang L, Hong Y. Baseline serum magnesium level and its variability in maintenance hemodialysis patients: associations with mortality. Kidney Blood Press Res. 2019 Mar;44(2):222-32.

32 Mizuiri S, Nishizawa Y, Yamashita K, Naito $\mathrm{T}$, Ono $\mathrm{K}$, Tanji C, et al. Hypomagnesemia is not an independent risk factor for mortality in Japanese maintenance hemodialysis patients. Int Urol Nephrol. 2019 Jun;51(6): 1043-52.

33 Rayner HC, Pisoni RL, Gillespie BW, Goodkin DA, Akiba T, Akizawa T, et al. Creation, cannulation and survival of arteriovenous fistulae: data from the dialysis outcomes and practice patterns study. Kidney Int. 2003 Jan; 63(1):323-30.

34 Young EW, Goodkin DA, Mapes DL, Port FK, Keen ML, Chen K, et al. The Dialysis Outcomes and Practice Patterns Study (DOPPS): an international hemodialysis study. Kidney International. 2000 Jun;57:S74-81.

35 Angkananard T, Anothaisintawee T, Eursiriwan S, Gorelik O, McEvoy M, Attia J, et al. The association of serum magnesium and mortality outcomes in heart failure patients: a systematic review and meta-analysis. Medicine. 2016 Dec;95(50):e5406.
36 Ohya M, Negi S, Sakaguchi T, Koiwa F, Ando R, Komatsu Y, et al. Significance of serum magnesium as an independent correlative factor on the parathyroid hormone level in uremic patients. J Clin Endocrinol Metab. 2014 Oct;99(10):3873-8

37 Alhosaini M, Leehey DJ. Magnesium and dialysis: the neglected cation. Am J Kidney Dis. 2015 Sep;66(3):523-31.

38 McGill RL, Weiner DE. Dialysate composition for hemodialysis: changes and changing risk. Semin Dial. 2017 Mar;30(2):112-20.

39 Shechter M, Sharir M, Labrador MJ, Forrester J, Silver B, Bairey Merz CN. Oral magnesium therapy improves endothelial function in patients with coronary artery disease. Circulation. 2000 Nov; 102(19):2353-8.

40 Turgut F, Kanbay M, Metin MR, Uz E, Akcay A, Covic A. Magnesium supplementation helps to improve carotid intima media thickness in patients on hemodialysis. Int urol Nephrol. 2008;40(4):1075-82.

41 Nie ZL, Wang ZM, Zhou B, Tang ZP, Wang SK. Magnesium intake and incidence of stroke: meta-analysis of cohort studies. Nutr Metab Cardiovasc Dis. 2013 Mar;23(3):16976.

42 Fang X, Wang K, Han D, He X, Wei J, Zhao $\mathrm{L}$, et al. Dietary magnesium intake and the risk of cardiovascular disease, type 2 diabetes, and all-cause mortality: a dose-response meta-analysis of prospective cohort studies. BMC Med. 2016 Dec;14(1):210.

43 Hénaut L, Massy ZA. Magnesium as a calcification inhibitor. Advances in Chronic Kidney Disease. 2018 May;25(3):281-90.

44 Altura B, Carella A, Gebrewold A, Murakawa T, Nishio A. Mg2+-Ca2+ interaction in contractility of vascular smooth muscle: $\mathrm{Mg} 2+$ versus organic calcium channel blockers on myogenic tone and agonist-induced responsiveness of blood vessels. Can J Physiol Pharmacol. 1987 Apr;65(4):729-45.

45 Gelli R, Scudero M, Gigli L, Severi M, Bonini $\mathrm{M}$, Ridi $\mathrm{F}$, et al. Effect of $\mathrm{pH}$ and $\mathrm{Mg} 2+$ on amorphous magnesium-calcium phosphate (AMCP) stability. J Colloid Interface Sci. 2018 Dec;531(7):681-92.

46 Ter Braake AD, Tinnemans PT, Shanahan CM, Hoenderop JGJ, de Baaij JHF. Magnesium prevents vascular calcification in vitro by inhibition of hydroxyapatite crystal formation. Sci Rep. 2018 Feb;8(1):2069.

47 Kircelli F, Peter ME, Sevinc Ok E, Celenk FG, Yilmaz M, Steppan S, et al. Magnesium reduces calcification in bovine vascular smooth muscle cells in a dose-dependent manner. Nephrol Dial Transplant. 2012 Feb;27(2): 514-21.

48 Brown EM, Gamba G, Riccardi D, Lombardi M, Butters R, Kifor O, et al. Cloning and characterization of an extracellular $\mathrm{Ca} 2+$-sensing receptor from bovine parathyroid. Nature. 1993 Dec;366(6455):575-80.
A Meta-Analysis of Serum Magnesium and Mortality in HD Patients
Kidney Dis 2021;7:24-33 DOI: $10.1159 / 000510513$ 